\title{
DETERMINANTS OF ENTREPRENEURIAL INTENTIONS: IMPACT OF CULTURE, GENDER, SELF-ESTEEM, AND SELF-EFFICACY ON UNIVERSITY STUDENTS
}

\author{
Aftab Hussain Rajar ${ }^{1 *}$, Imamuddin Khoso², and Misbah Bibi Qureshi ${ }^{3}$
}

\begin{abstract}
The main objective of this study is to examine the socio-cultural and individual factors that influence the entrepreneurial intentions among students studying the Public Sector Universities in Sindh Province. In the cultural context, three variables i.e., collectivism, power distance and uncertainty avoidance, one variable in social context i.e., gender-role orientation and two variables in individual context i.e., self-esteem and self-efficacy are used and empirically tested through the SEM model. It was found that all three components of culture have been negatively correlated with entrepreneurial intentions. These results infer that the prevalent family culture in Sindh Province is not supportive of entrepreneurial intention as respondents found strict control of elder family members over their future career choices, depressing and a hurdle in their way to become entrepreneurs. The feminist gender orientation of an individual is found to have a negative effect on the development of entrepreneurial spirit. This stands in support of the dominant notion that masculine gender orientation is required to become a vibrant entrepreneur. Under the masculine approach, an individual prefers to have characteristics like tough, assertive, calculated and pursue material success in life; contrary to the feminist orientation which focuses on being tender, modest, and pursuing the relational quality in life. The findings reveal that individuals who carry a high worth for themselves and believe in their abilities to address the challenges of running a business tend to have more entrepreneurial intentions. Lastly, the role of gender as moderator shows that the cultural barriers have a more negative impact on the formation of entrepreneurial intents of female than male students. Based on the findings of this study and informal observations from students during the field, it is recommended that the policymakers should invest in strengthening the entrepreneurial ecosystem, focusing on the provision of entrepreneurial educational infrastructure, building family \& culture support structures that can help potential students enhance their self-esteem, self-efficacy and get necessary socio-cultural capital to become successful entrepreneurs.
\end{abstract}

Keywords: Entrepreneurship; Entrepreneurial Ecosystem; Entrepreneurial Intentions; Culture; Gender; Self-Efficacy; Self-Esteem.

\footnotetext{
${ }^{1}$ PhD Candidate, IBA, University of Sindh, Jamshoro-Sindh, Pakistan. Email: aftab rajar@ hotmail.com

${ }^{2}$ Professor, IBA, University of Sindh, Jamshoro-Sindh, Pakistan. Email: imam.khoso@usindh.edu.pk

${ }^{3}$ Professor, Institute of Gender Studies, University of Sindh, Jamshoro. Email: misbahhq@ gmail.com

*Corresponding Author
} 


\section{INTRODUCTION}

Since the industrial revolution, particularly from 1960s and onwards, the developed countries have conclusively evidenced that big established enterprises cannot generate a net rise in employment opportunities, causing a sustainably high unemployment. That finding led the political leaders of developed countries to promote the culture of creation of new albeit small firms which are rightfully considered to be an engine to create new jobs (Aiginger \& Tichy, 1991; Davidsson et al., 1995). The economists argued that one of the most effective tools to address the chronic problem of unemployment, to raise living standard of people, and to achieve socio-economic growth at regional and national level, is to start the entrepreneurial ventures in every corner of the country. Consequently, the interest in understanding the entrepreneurship phenomena has been developed by the researchers across the developed countries.

Upon successful launch of entrepreneurial businesses and their efficacy in addressing socioeconomic issues in the West, the developing countries followed the suit and started focusing on the promotion of entrepreneurial environment in which new small firms can be established in a bid to achieve economic growth. In addition of the role of entrepreneurship in generating national competitiveness, wealth and prosperity, the thriving entrepreneurial culture also helps individuals to meet their personal goals and lead fulfilling life (Hyun, et al., 2020). It is with this background that this study is focused on understanding entrepreneurship phenomena. Though there are a number of areas through which entrepreneurship can be researched, but the formation of entrepreneurial intention has gained much traction among researchers. The entrepreneurial opportunities are capitalized by the individuals who have intent and readiness to become an entrepreneur. It is well acknowledged that entrepreneurship does not happen in a vacuum. It is the process which is deeply rooted in a web of social and cultural settings (Reynolds, 1992). It implies that an individual, group or an organization can possess the entrepreneurial potential if their intentions are developed prior for the desired actions to take place in the future. Entrepreneurship clearly represents intentionally planned behavior and thus processed based, and theory driven models would be appropriate to understand the development of entrepreneurial intentions (Al-Ghazali et al., 2021). The intentions are often perception driven and hence can vary across the people and situations.

It is well documented that entrepreneurship is the result of well-planned intentions. The development of a business plan before a venture is started clearly manifests that the entrepreneurial activities occur in planned way. Even in economic conditions like lay-offs and downsizing, the individuals with high entrepreneurial intentions are catalyzed to start their own business. The new business is established after sustainable thinking and efforts over time and 
thus researchers are interested in examining the thinking of potential students in pre-business phase ( $\mathrm{Lu}$ et al., 2021). The exploration of entrepreneurial intentions has some distinctive benefits to understand entrepreneurship. Firstly, the establishment of a new firm is a rare occurrence, and the factors deriving that individual action can potentially manifest in other behaviors and thus can be well understood through theory-driven and testable intentional models. Secondly, given the growing events of downsizing, it is critical to inculcate the entrepreneurial spirit in the minds of our students I order to make them self-employable. Thirdly, for developing effective policy intervention to stimulate the creation of new firms, it is more insightful to understand the factors that are being found appealing by the individuals who are planning to enter into entrepreneurial business than to know the characteristics of the individuals who are already in business. Finally, the determination of the role of key factors in developing entrepreneurial intentions would help academic institutions to devise curriculum and training programs to turn potential students into real entrepreneurs (Abbasianchavari \& Moritz, 2021). Therefore, this study attempts to understand the factors influencing the formation of entrepreneurial intentions among youth in Sindh Province Pakistan.

\section{Entrepreneurship and Planned Intentions: Theoretical Perspective}

The entrepreneur word originally came from the French words "entre and preneur", meaning to undertake and to take between (Bird \& West, 1998). The concept of entrepreneurship has been evolutionary in nature and been defined $\&$ refined during the periods of classical (up to 1880), neoclassical (up to 1980) and modern (up to-date) economic history. In the era of classical economics, the economists Cantillon, Adam Smith, and Say were the prominent authors who attempted to theorize the entrepreneurship phenomenon. The Cantillon (1755) was the first to formally theorize the entrepreneurship as the process of intermediation in which an entrepreneur undertakes the risk in exchange and circulation of merchandise goods (Casson, 1999). The key elements were the role of intermediary and risk taking by an individual in trade. The Cantillon's concept of entrepreneurship centered around intermediation, might have been influenced by the then economic environment in which trade was done based on mercantile approach (Dana, 2014). The economic activities were majorly controlled by feudal system. Later on, the classical economist Adam Smith (1776) through his concepts laid the foundation of new economic order, connecting private entrepreneurs with economic theories.

Smith highlighted the importance of labor, land and capital as wealth of a nation in which entrepreneurs are those who launch firms for building personal profit under the invisible hand concept Jean Say (1785) build on the work of Admin Smith and developed an economic concept commonly referred as Say's Law which conceptualized that entrepreneurs are those 
who are able to create demand for the new products, produce mass production through establishment of an enterprise, and increase the well-being of the majority (Aspromourgos, 2013). Under the Say's Law, Say argued that supply of entrepreneurial products generates its own demand in the market and causes the increase in the wealth of the founder and raise the living standard of all the people.

The era of neo classical economic thoughts began in the late 19 century. The political, social, and technological advances during this era brought about a scientific and market-based economic structures which were significantly different from the feudal and medieval orders of socioeconomic system. With transitioning of feudal economic order into open market-driven economic system, the modern monetary system was evolved using bills of exchange and other innovative payment modes (Freiling, 2007). The Marshal was the first economist in neoclassical period to refine the concept of entrepreneurship. Contrary to Adam Smith, he argued that the factors of production are four: labor, land, capital, and enterprise, thereby identifying the necessity of an arranger who should amass all the necessary resources, takes risk, provides leadership, and produces products in huge quantity using an enterprise.

It has been maintained that entrepreneurship carries the characteristics of creation of new thing, innovation and dealing with uncertainty. Entrepreneurs tend to figure out not only unique products but also coin new methods of production and new forms of enterprises (Low \& MacMillan, 1988).

Finally, the modern theorists have explained the entrepreneurship using certain salient features and characteristics including; new entrance into the market, establishment of a new organization (Low \& MacMillan, 1988), a planned activity to start and manage a growing business profitably, identifying opportunity and combining resources in a unique way to produce a substantial impact in the market, to pursue an opportunity and bring the product or service in the market for commercialization irrespective of individual's resources in possession (Messeghem, 2003), the creation of something distinct using time and energy while bearing psychological, social, and financial risks with the hope gaining monetary rewards and seeking a sense of personal fulfillment (Kearney et al., 2008).

\section{PROBLEM STATEMENT}

Entrepreneurship is fundamentally the result of a thinking process that prefers grabbing of an opportunity over risk of losing. The process of identifying the opportunities to run an enterprise is clearly an intentional \& deliberate process (Krueger et al., 2000), and thus, it is important to thoroughly examine the process of formation of entrepreneurial intentions. The understating of the development of entrepreneurial intentions is critical in predicting the actual 
entrepreneurship in a nation. Before making a career decision such as starting a venture, we tend to think for it first and then analyze the market environment, collect the market cues, construct a viable venture proposition, and finally act upon it as planned. The psychological theories have long predicted the human behaviors in different set-ups exclusively based on an individual's intentions.

The decision to start a business develops over time and takes a lot of planning, hence can be well explained through the approaches of planned behavior which in turn is the result of prior intentions. The empirical models conceptualized on the intentions have been proven parsimonious, coherent, robust, and generalizable in the field of entrepreneurship (Carsrud et al., 1993). However, controversy still exists in terms of the selection of factors that should be anchored to build a comprehensive entrepreneurial intention model. The findings of early research show that primarily intention models exclusively focused on personal and psychological characteristics of an individual who plan to start a business in the future. That trait-based approach of venture founder has failed to explain the significant portion of entrepreneurship phenomena. Further, it was found that the family background of an individual is more significant determinant in explaining the entrepreneurial intent than individual's psychological characteristics (Reynolds, 1992).

Given the limited explanatory power of trait- and characteristics-based models, the researchers suggested through analysis using aggregate approach to include regional and national factors influencing the entrepreneurial behaviors of individuals (Davidsson et al., 1995). Particularly, it was advised to explore and understand the thinking process, career preferences, characteristics of would-be entrepreneurs in conjunction with social and cultural factors at the pre-start period of business. Thus, in order to fully grasp the phenomenon of what derives students to start a new enterprise, an intentional model including social, cultural, and individual characteristics based on the assumptions of Theory of Planned behavior (TPB) and the Shapero's Entrepreneurial Event Model (SEEM) is framed for empirical test. Secondly, the conceptual model of this study has been tested in the line of gender (i.e., male and female) as moderating variable.

The research studies on entrepreneurial intentions and the role of gender have explored two aspects. First, the biological differences between the physical composition of male and female. Second, is a gender orientation which leads to a different set of gender-induced beliefs, values, and socialization. Gender role orientation is a social phenomenon which differentiates male and female along the lines of masculinity and femininity instead of gender sex differences. The male and female living in the same community tend to adopt attitudes and behaviors which are 
shaping up their character and personality as typical masculine or feminine. In our social system some tasks are perceived as masculine like to be entrepreneur while others are viewed as feminine as nursing and these stereotyped attitudes towards different professions substantial influence a student's decision to choose and pursue a future career. To measure the gender orientation of an individual, Bem (1974) developed Bem's Sex Role Inventory (BSRI) which is a multiple item attitudinal instrument. Based on the scores an individual obtains on each item scale of BSRI, he or she is categorized as masculine or feminine in terms of gender role orientation (Holt \& Ellis 1998). Therefore, in this study the gender is used as moderator and as in independent variable in the shape of gender role orientation.

\section{LITERATURE REVIEW}

The literature on entrepreneurship shows that situational factors such as environmental cues and individual factors such as personality traits have been found to be the predictors of entrepreneurial intention development. It is well recognized that entrepreneurial firms are the result of persons' planned intentions and their ensuing actual behavior (Kautonen et al., 2015). The entrepreneurship is basically a behavior which is intentionally planned before actual action occurs (Krueger \& Carsrud, 1993). The culture has a significant impact on the pace and intensity by which entrepreneurial intentions are being formed in the minds of people at various stages of their lives. The cultural trends, beliefs, values, and taboos are deeply engraved in the masses which have a strong bearing on thinking process of individuals who dare to plan, have an intent, and are determined to do entrepreneurial business (Stephan \& Uhlaner, 2010). The cultural traditions can support or demotivate the formation of entrepreneurial intentions. The entrepreneurial readiness can be made more mature a\& resilient through inculcating positive and encouraging cultural values into the minds of would-be entrepreneurs (Morales \& Holtschlag, 2013). Later on, Schlaegel and Koenig (2014) called on researchers to deeply consider the cultural traditions in studying up the entrepreneurial intentions among people in the developing countries. Subsequently, insisted to include cultural dimensions in research models explaining the entrepreneurship phenomena.

It is in this context that in this study the impact of cultural dimensions is assessed on the formation process of entrepreneurial intentions. The culture is an umbrella term which encompasses all the factors directly or indirectly related to an individual and group's activities. Hofstede (2011), a prominent researcher in the domain of culture, defined the term culture as a cumulative mental programing that distinguishes one individual member from another category or group of people. The characteristics designing that mental programing are the attitudes, values, motivations, and certain behavioral patterns which are transmitted from one generation to another. 
It is widely acknowledged that a person's intentions and subsequent behavioral are largely in consistence with the practices and tradition of the culture an individual is subscribed to and engaged with. The entrepreneurial literature shows that potential entrepreneur does not only consider his or her own set of skills, abilities, and competence level, but also take into account how the reward and failure in business is perceived in a given cultural setting. According to Newbery et al. (2018), the development of the perceived entrepreneurial identification, a fundamental condition to derive a student towards adoption of entrepreneurial career, is significantly influenced by the cultural values in a society.

The previous research studies show that culture has three approaches (i.e., Pull, Social \& Moral Legitimation and Push Approaches) relevant to the entrepreneurial activities. The Pull Approach is featured by pro-entrepreneurial characteristics and traits which promote the entrepreneurial spirit among the people. It encourages the development of psychological values and traits that are in congruence with the formation an environment in which entrepreneurship is highly valued and rewarded, resulting in more individuals to become entrepreneurs (Thurik \& Dejardin, 2011). Secondly, the Social and Moral Legitimation Approach is also considered pro-entrepreneurship culture. It focuses to fostering the values in a society which highly appreciated the entrepreneurial actions on the ground of serving the needs of community in innovative ways. Consequently, society assigns high asocial and moral status to the people who became self-employed and provided employment opportunities to others while catering the specific needs of consumers, making their own as well as the lives of others better off (Fayolle et al., 2014).

Contrary to previous two approaches, the third one is Push Approach which is set out to discourage the entrepreneurial activities. Individuals with entrepreneurial intent and potent find themselves at odds with the dominant cultural values which are against the taking risk and working in an uncertain environment. In such culture there is big difference between individual opinion and family choice, pushing the person away from starting own business (Noorderhaven et al., 2004). A wide body of research reports that the prevailing culture significantly determines the quantity and quality of entrepreneurial businesses in a country (Kibler et al., 2014). Given these findings, it is reasonable to assume that the cultural dimensions would influence the formation of entrepreneurial intentions among the students studying at various academic institutions in Sindh province Pakistan. In this study, the three key cultural dimensions (i.e., individualism versus collectivism, power distance and uncertainty avoidance) given by Hofstede et al., are chosen which are expected to influence intimal and behavioral patterns of individuals. Individualism aspect of culture refers to the communities characterized by independent and free relationships between individuals and family and other social groups. 
It encourages the emotional and intellectual independence of an individual within a society, a desirable condition for people to take entrepreneurship as their career choice (Hofstede, 2011). Contrary, the collectivism-oriented cultures tend to be highly dependent in which individuals are closely associated with family members and other dominant social groups and individuals are expected to behave in lines with family and other social values of decision-makers in the society.

Power distance is an important dimension of culture indicating the control-nexus between individuals and other members of society. High power distance environment makes potential individuals think the chances of success on the journey of entrepreneurship are unequally skewed in favor of those who move in congruence with order of power (Rusu et al., 2019), thereby discouraging the formation of entrepreneurial intent build up among students who wish to be independent in their career choices. In contrast, it is intrinsically appealing and empowering to the minds of individuals who live and interact in low power distance cultures. Uncertainty avoidance points to the degree to which an individual is feeling intimidated by uncertain and unknown scenarios in future occurrences. It is conducive for entrepreneurship to flourish in cultural set-ups which carry low level of uncertainty avoidance and encourages to hold some measurable beliefs in the future outcomes.

Entrepreneurship requires individuals to carry high degree of self-respect, self-value, and selfefficacy, resulting into high belief in one's abilities (Bogatyreva et al., 2019). Based on the extensive review of literature above, the following research hypotheses are developed, tested and discussed in subsequent sections.

H1: The collectivism (as a component of culture) significantly influences entrepreneurial intentions of students (EIS).

H2: The Power Distance (as a component of culture) significantly affect EIS.

H3: The Uncertainty Avoidance (as a component of culture) has significant impact on EIS.

H4. Feminist gender orientation significantly influences EIS.

H5. Self-Esteem is significant determinant to EIS.

H6. Self-Efficacy is significant determinant to EIS.

H7: The Gender significantly moderated relationship between the collectivism and entrepreneurial intentions such that impact is strengthened for female than male students.

H8: The Gender significantly moderated relationship between the Power Distance and entrepreneurial intentions such that effect gets stronger for female than male students.

H9: The Gender significantly moderated relationship between the Uncertainty Avoidance and entrepreneurial intentions such that impact is strengthened for female than male students. 
H10. The Gender significantly moderated relationship between the Feminist gender orientation and entrepreneurial intentions such that effect gets stronger for female than male students.

H11. The gender significantly moderated relationship between the self-esteem and entrepreneurial intentions such that impact is strengthened for female than male students.

H12. The gender significantly moderated relationship between the self-efficacy and entrepreneurial intentions such that effect get stronger for female than male students.

\section{RESEARCH METHODOLOGY}

The student respondents have been commonly used in entrepreneurial intentions (Liñán, \& Chen, 2009). Thus, the population of this study comprised the final years students majoring in four fields: commerce \& business administration, computer \& information technology, engineering, and agriculture across the public sector universities in Sindh Province. As per international survey standards, 1000 survey questionnaires were distributed, of which 813 questionnaires were returned, 09 questionnaires were found with a lot of missing values and were separated; hence 804 completely filled-in questionnaires were finalized for analysis, indicating the valid participation rate of $80.40 \%$. The sample of this study is final year students who are on the verge of entering into market and thus to make their career decisions of getting a job or becoming self-employed. In this study, stratified random sampling technique has been used.

In first phase, the number of final students studying the four-degree programs were selected and in second phase, the sample size from each discipline was made based on the proportionate sampling size method. The list of students enrolled in each targeted discipline has been obtained from director admission offices through registrar office of each public sector universities (i.e., University of Sind, Mehran University of Engineering \& Technology Jamshoro, Karachi University, Benazir Bhutto Shaheed University Lyari Karachi, Shah Abdul Latif University Khairpur, Sukkur IBA University and Sindh Agriculture University Tandojam. In this study quantitative approach was used in data collection and thus a survey questionnaire was adopted with slight modification in wording. The survey questionnaire consisted of the variables of culture (Bogatyreva et al., 2019; Hofstede, 2011), gender orientation (Perez-Quintana, et al., 2017), Self-esteem (Rosenberg, 1965), Self-efficacy (Luszczynska et al., 2005) and entrepreneurial intention (Liñán, \& Chen, 2009). The pilot testing was conducting before administering the survey questionnaire for full-scale data collection. Keeping into view, the nature of latent variables and the moderating role of gender, Structural Equation Model (SEM) is primarily used to analyze the collected primary data. The 
constructs were checked for reliability using Cronbach's' alpha, Rho_A, composite reliability and Average Variance Extracted (AVE) and Discriminant Validity using Fornell-Larcker Criterion and Heterotrait-Monotrait Ratio (HTMT). PLS latest version software was used to analyze the data.

\section{DATA ANALYSIS AND DISCUSSION}

The participants of this study were the students of final year who were about to enter into a labor market either doing a job in any firm or starting off their own business. The participants were asked about their gender, degree program and its discipline. The $\mathrm{N}$ of this study was 804 , of which $59 \%$ were male students and remaining $41 \%$ were females. $47 \%$ of students were doing bachelor's degree and 53\% were enrolled in master's degree program. With respect to discipline of the degree, majority (i.e., 31\%) of the respondents were enrolled in the field of commerce \& business administration, followed by $27 \%$ of respondents were registered in the discipline of computer \& information technology. The least (i.e., 16\%) of participants were studying in the field of agriculture and the remaining $26 \%$ of respondents were from the discipline of engineering.

\section{Convergent Reliability of Constructs}

The data was examined for determining convergent reliability; the cut-off values for Cronbach's alpha, rho_A and composite reliability are 0.7 and that is if a construct has reliability statistics above 0.7 , it is said to be reliable measure. In this study all of seven constructs used are having reliability values above 0.7 indicating that reliability is established. Further, the threshold value for AVE is 0.5 , and in this study all constructs meet that requirement as all values of AVE are above 0.5 level.

Table 1. Convergent Reliability of Constructs

\begin{tabular}{|l|c|c|c|c|}
\hline & Cronbach's Alpha & rho_A & Composite Reliability & AVE \\
\hline COLL & 0.767 & 0.778 & 0.852 & 0.594 \\
\hline EI & 0.793 & 0.794 & 0.858 & 0.548 \\
\hline GO & 0.808 & 0.810 & 0.867 & 0.566 \\
\hline HPD & 0.833 & 0.841 & 0.889 & 0.667 \\
\hline HUA & 0.748 & 0.786 & 0.840 & 0.571 \\
\hline SE & 0.742 & 0.752 & 0.831 & 0.501 \\
\hline SEF & 0.843 & 0.850 & 0.888 & 0.614 \\
\hline
\end{tabular}

Source: This Study

\section{Discriminant Validity}

Once the reliability of constructs used in this study are established, the next requirement is to gauge the discriminant validity of constructs. The discriminant validity indicates the degree to which a construct is empirically distinct from other explanatory variables used in the structural 
equation model. It is desirable that explanatory constructs should be both conceptual and empirical different from one another in order to mitigate the issue of multicollinearity among independent variables.

For determining discriminant validity, the Fornell-Larcker Criterion, Heterotrait-Monotrait Ratio (HTMT) and Variance Inflation Factor (VIF) tests are applied. The results of FornellLarcker Criterion show that the diagonal values, highlighted in bold green are greater than the corresponding values of the other constructs indicating that discriminant validity is established.

Table 2. Discriminant Validity: Fornell-Larcker Criterion

\begin{tabular}{|l|r|r|r|r|r|l|l|}
\hline & \multicolumn{1}{|c|}{ COLL } & EI & GO & HPD & HUA & SE & SEF \\
\hline COLL & 0.771 & & & & & & \\
\hline EI & -0.648 & 0.740 & & & & & \\
\hline GO & 0.617 & -0.659 & 0.752 & & & & \\
\hline HPD & 0.511 & -0.524 & 0.512 & 0.817 & & & \\
\hline HUA & 0.574 & -0.610 & 0.622 & 0.433 & 0.756 & & \\
\hline SE & 0.536 & -0.435 & 0.502 & 0.544 & 0.507 & 0.708 & \\
\hline SEF & -0.320 & 0.410 & -0.297 & -0.239 & -0.551 & -0.527 & 0.784 \\
\hline
\end{tabular}

Source: This Study

Similarly, HTMT is used to analyze discriminant validity. As per HTMT criterion, no correlation should go above 0.85 range. The results show that all the values of HTMT are below the threshold value if 0.85 indicating that all constructs are empirically distinctive from one another. Moreover, PLS generates confidence intervals for HTMT values, and the desired output is that the value of 01 should not fall within $2.5 \%$ and $97.5 \%$ range of confidence values. The results show that in no case there is the value of 01 between confidence intervals for HTMT values, further manifesting the strong discriminant validity.

Table 3. Discriminant Validity: Heterotrait-Monotrait Ratio (HTMT)

\begin{tabular}{|l|r|r|r|l|l|l|l|}
\hline & COLL & EI & GO & HPD & HUA & SE & SEF \\
\hline COLL & & & & & & & \\
\hline EI & 0.816 & & & & & & \\
\hline GO & 0.783 & 0.812 & & & & & \\
\hline HPD & 0.618 & 0.635 & 0.618 & & & & \\
\hline HUA & 0.737 & 0.765 & 0.770 & 0.529 & & & \\
\hline SE & 0.711 & 0.567 & 0.647 & 0.697 & 0.684 & & \\
\hline SEF & 0.386 & 0.494 & 0.355 & 0.279 & 0.740 & 0.658 & \\
\hline
\end{tabular}

Source: This Study

Additionally, the data was investigated for multicollinearity among explanatory variables used in the model of this study. Variance Inflation Factor (VIF) is applied to check multicollinearity. 
The VIF values below 05 indicate that there is no serious multicollinearity issue among predictors. The results in both tables show that at construct and individual item level, no VIF value is above 05 indicating that all the constructs and their items are unique, and no serious multicollinearity exists.

\section{Structural Model: Direct Path Coefficients}

In the context of entrepreneurship, the culture generally deals with people's relationship to power and authority, perception of self in comparison to others in the society, and the approaches to address uncertainties, ambiguities, risks, conflicts, and aggressive behaviors. It is concluded from the results of gender orientation that though gender orientation high in masculinity is considered favorable and supportive for initiating entrepreneurial activity (Busenitz and Lau 1996), but male and female aspirants experience it very differently. In the same line, Hussain et al., (2021) demonstrated that power distance is positively associated with inequality in perceived gender-based roles and in high gendered societies, the male supremacy is normalized and legitimized. Parboteeah et al., (2008) reported that in male-dominant societies, females are likely to be placed at the bottom of decision-making authoritative hierarchy and surprisingly, all the social members are ready to accept and respect the inequality in power hierarchy. The results related to self-esteem strongly demonstrate that individuals with high self-esteem tend to have higher volume of entrepreneurial intentions (Pyszczyn-ski, et al., 2004).

Finally, self-efficacy is found to be playing a critical role in building up of entrepreneurial intentions among students (Meoli al., 2020). A person's judgment regarding his or her selfefficacy beliefs are also shaped by a person's access to resources and the assessment of hurdles that may influence future career performance (Mahfud et al., 2020). Students with high selfesteem and self-efficacy often stay in active pursuit of materialistic gains and hence, they prefer to follow the careers that have a real potential to bring them a fortune and take them to the height of the ladder of social success and power status in the community. With regard to gender as moderating variable, the results show that the non-supportive cultural traditions hurt more would-be female aspiring entrepreneurs than male students with entrepreneurial intention to launch an innovative business after completion degree. This finding is in line with the results of Biswas et al., (2021) evidenced that the cultural dimensions exert more level of stress on female students than on male students. The cultures in which women are expected to do household chores, to look after the children and elderly family members, tend to consider the cultural barriers more significant in their decision to become entrepreneur. Whereas the men in such cultures are expected to be assertive, tough, competitive and to achieve power, status, and success outside the home life. When a profession like entrepreneurship is linked to man 
gender then women, this may underestimate their abilities to be successful and hence try to avoid entering into such careers.

Table 4. Structural Model: Direct Path Coefficients

\begin{tabular}{|l|c|c|c|c|c|c|c|}
\hline & Original Sample & Sample Mean & Standard Deviation & T Statistics & P Values & $2.5 \%$ & $97.5 \%$ \\
\hline COLL $>$ El & -0.303 & -0.301 & 0.044 & 6.950 & 0.000 & -0.386 & -0.215 \\
\hline$G O>$ El & -0.313 & -0.315 & 0.042 & 7.404 & 0.000 & -0.402 & -0.235 \\
\hline HPD $>$ El & -0.189 & -0.189 & 0.031 & 6.053 & 0.000 & -0.251 & -0.128 \\
\hline HUA $>$ El & -0.138 & -0.139 & 0.044 & 3.149 & 0.002 & -0.225 & -0.055 \\
\hline SE $>$ El & 0.153 & 0.149 & 0.041 & 3.138 & 0.000 & 0.068 & 0.227 \\
\hline SEF $>$ El & 0.180 & 0.178 & 0.039 & 4.643 & 0.000 & 0.105 & 0.257 \\
\hline
\end{tabular}

Source: This Study

The Gender was used as moderator to assess whether the impact of explanatory variable vary among male and female students as entrepreneurship is gender sensitive in developing countries. In total the gender as moderator shows positive and significant results with three explanatory variables related to culture (i.e, collectivism, higher power distance and high uncertainty avoidance) indicating that strict culture in terms of family control over student's future career decisions affect female mire than male in respect of their intents to begin a new business in the future. Whereas for the remaining explanatory variables of gender orientation, self-esteem, and self-efficacy the results of moderation are statistically non-significant indicating that self-esteem and self-efficacy are equally important derivers to entrepreneurial intentions for male and female students. Similarly, female, and male respondents equally believe the masculine role in promoting the entrepreneurial spirit among themselves.

Based on the results of moderation, it is argued that the individualistic difference in male and female students are systematic in nature and hence, it needs to be addressed at institutional level to uplift the level of individualism among female students at par with their male counterparts. Entrepreneurial barriers emanating from cultural traditions have a tendency to create stereotypes with respect to label certain professions like entrepreneurship as masculine which in turn shape up gender orientations viewing which careers are suitable for males or females in a given society (Shinnar et al., 2014). Consequently, under the influence of those societal stereotype believes, individuals choose the occupations which are appropriate to their gender-sex. It has been argued that stereotypes related to gender are not only driven by an individual's biological sex, but also reflecting the acceptable norms for how a man or women should behave and roles he or she should play in a community, indicating that gender stereotypes are of both descriptive and prescriptive in nature (Ahl, 2006). These stereotypes are not of only typical phenomena to developing countries but also are found pervasive in 
developed countries too. Schein et al. (1996) found that typecasting of gender exits across the world with the evidence that male students in United Sates, United Kingdom, Japan, and Germany are considered more suitable for managerial positions because of their masculine traits than female students.

Table 5. Structural Model: Moderator Path Coefficients

\begin{tabular}{|c|c|c|c|c|c|}
\hline & Original Sample & Sample Mean & Standard Deviation & T Statistics & P Values \\
\hline COLL $\rightarrow$ EI & -0.307 & -0.307 & 0.044 & 7.039 & 0.000 \\
\hline GO $\rightarrow$ El & -0.300 & -0.305 & 0.043 & 7.015 & 0.000 \\
\hline Gender $>$ EI & 0.055 & 0.052 & 0.020 & 2.708 & 0.007 \\
\hline HPD $\rightarrow$ EI & -0.189 & -0.190 & 0.030 & 6.275 & 0.000 \\
\hline HUA $\rightarrow$ EI & -0.147 & -0.140 & 0.044 & 3.318 & 0.001 \\
\hline Moderating Effect (Gender $\left.{ }^{*} \mathrm{COLL}\right)$-> EI & 0.077 & 0.074 & 0.038 & 2.021 & 0.044 \\
\hline Moderating Effect (Gender ${ }^{*} \mathrm{G}$ ) $)>$ EI & -0.040 & -0.031 & 0.047 & 0.857 & 0.392 \\
\hline Moderating Effect (Gender*HPD) -> El & 0.112 & 0.111 & 0.047 & 2.419 & 0.016 \\
\hline Moderating Effect (GenderHUA) -> El & 0.121 & 0.121 & 0.043 & 2.801 & 0.005 \\
\hline Moderating Effect (Gender ${ }^{*}$ SE) -> EI & 0.043 & 0.043 & 0.041 & 1.071 & 0.284 \\
\hline Moderating Effect (Gender ${ }^{*}$ SEF) -> El & 0.003 & 0.004 & 0.040 & 0.086 & 0.931 \\
\hline SE > EI & 0.144 & 0.142 & 0.042 & 3.405 & 0.001 \\
\hline SEF $\rightarrow$ EI & 0.175 & 0.175 & 0.040 & 4.345 & 0.000 \\
\hline
\end{tabular}

Source: This Study

\section{CONCLUSION}

At individual or organizational levels, for real entrepreneurship to exist, the protentional to become entrepreneur is a necessary condition. The actual entrepreneurial activity is the outcome of an entrepreneurial intention. This holds true to the people studying in higher education and innovative employees working in firms. Drawing upon social psychology, cultural norms and an individual's personal characteristics, the conceptual model of this study is framed to test the entrepreneurship potential through entrepreneurial intentions of students. In this study six direct hypotheses were developed and as per path coefficients all those six direct hypotheses were fully supported. Further, six moderating hypotheses were formulated, of which three were supported and the results could not lend support to the remaining three moderating hypotheses. It is found that all three components of culture (i.e., collectivism, high power distance and high uncertainty avoidance) have been negatively correlated with entrepreneurial intentions. These results infer that the prevalent family culture in Sindh Province is not supportive to entrepreneurial intention as respondents found strict control of elder family members over their future career choices, depressing and a hurdle in their way to become entrepreneur. The feminist gender orientation of an individual is found to have a negative effect on the development of entrepreneurial spirit. This stand in support of the dominant notion that masculine gender orientation is required to become a vibrant entrepreneur. Under masculine approach, an individual prefers to have characteristics like tough, assertive, calculated and pursue material success in life; contrary to the feminist orientation which focuses on being tender, modest and to pursue the relational quality in life. The findings reveal that the individuals who carry high worth of themselves and believe in their 
abilities to address the challenges of running business tend to have more entrepreneurial intentions. The role of gender as moderator shows that the cultural barriers have more negative impact on the formation of entrepreneurial intents of female than male students. Based on the findings of this study, formal and informal observations from students during field, it is recommended that the policy makers should invest in strengthening entrepreneurial ecosystem, focusing on provision of entrepreneurial educational infrastructure, building family \& culture support structures that can help potential students enhance their self-esteem, self-efficacy and get necessary socio-cultural capital to become a successful entrepreneurship. 


\section{REFERENCES}

Abbasianchavari, A., \& Moritz, A. (2021). The impact of role models on entrepreneurial intentions and behavior: a review of the literature. Management Review Quarterly, 71(1), 1-40.

Ahl, H. (2006). Why research on women entrepreneurs needs new directions. Entrepreneurship theory and practice, 30(5), 595-621.

Aiginger, K., \& Tichy, G. (1991). Small firms and the merger mania. Small Business Economics, 3(2), 83-101.

Al-Ghazali, B. M., \& Afsar, B. (2021). Narcissism and entrepreneurial intentions: the roles of entrepreneurial self-efficacy and environmental complexity. The Journal of High Technology Management Research, 32(1), 100395.

Aspromourgos, T. (2013). Entrepreneurship, risk, and income distribution in Cantillon's Essai. In Classical Political Economy and Modern Theory (pp. 121-135). Routledge.

Bird, B. J., \& West III, G. P. (1998). Time and entrepreneurship. Entrepreneurship theory and practice, 22(2), 5-9.

Biswas, A., \& Verma, R. K. (2021). Attitude and alertness in personality traits: a pathway to building entrepreneurial intentions among university students. The Journal of Entrepreneurship, 30(2), 367-396.

Bogatyreva, K., Edelman, L. F., Manolova, T. S., Osiyevskyy, O., \& Shirokova, G. (2019). When do entrepreneurial intentions lead to actions? The role of national culture. Journal of Business Research, 96, 309-321.

Busenitz, L. W., \& Lau, C. M. (1996). A cross-cultural cognitive model of new venture creation. Entrepreneurship theory and practice, 20(4), 25-40.

Carsrud, A., Gaglio, C., and Kernochan, R. (1993). Demographics in entrepreneurship research: Guidelines for the use of demographic data. R. Brockhaus and J. Katz, eds., Research in Firm Emergence, Growth, and Entrepreneurship, 1.

Casson, M. (1999). Entrepreneurship and the Theory of. Entrepreneurship, Small and MediumSized Enterprises and the Macroeconomy, 45.

Dana, L. P. (2014). Asian models of entrepreneurship - from the Indian Union and Nepal to the Japanese Archipelago: Context, policy, and practice.

Davidsson, P., Lindmark, L., \& Olofsson, C. (1995). Small firms, business dynamics and differential development of economic well-being. Small Business Economics, 7(4), 301-315.

Fayolle, A., Liñán, F., \& Moriano, J. A. (2014). Beyond entrepreneurial intentions: values and motivations in entrepreneurship. International Entrepreneurship and Management Journal, 10(4), 679-689. 
Freiling, J. (2007). SME Management-What Can We Learn from Entrepreneurship Theory? Available at SSRN 984658.

Hofstede, G. (2011). Dimensionalizing cultures: The Hofstede model in context. Online readings in psychology and culture, 2(1), 2307-0919.

Holt, C. L., \& Ellis, J. B. (1998). Assessing the current validity of the Bem Sex-Role Inventory. Sex roles, 39(11), 929-941.

Hussain, I., Nazir, M., Hashmi, S. B., Shaheen, I., Akram, S., Waseem, M. A., \& Arshad, A. (2021). Linking green and sustainable entrepreneurial intentions and social networking sites; the mediating role of self-efficacy and risk propensity. Sustainability, 13(13), 7050 .

Hyun J.W. OK, B. H., Chang, E. S., \& Yang, J. M. (2020). A study on the effect of social support on entrepreneurial intentions and entrepreneurial behaviors: mediating effects of entrepreneurial self-efficacy and entrepreneurial intentions. Asia-Pacific Journal of Business Venturing and Entrepreneurship, 15(1), 151-165.

Kearney, C., Hisrich, R., \& Roche, F. (2008). A conceptual model of public sector corporate entrepreneurship. International Entrepreneurship and Management Journal, 4(3), 295 313.

Kautonen, T., Van Gelderen, M., \& Fink, M. (2015). Robustness of the theory of planned behavior in predicting entrepreneurial intentions and actions. Entrepreneurship theory and practice, 39(3), 655-674.

Kibler, E., Kautonen, T., \& Fink, M. (2014). Regional social legitimacy of entrepreneurship: Implications for entrepreneurial intention and start-up behaviour. Regional Studies, 48(6), 995-1015.

Krueger. N. F. \& Carsrud. A. L. (1993), Entrepreneurial intentions: Applying the theory of planned behavior, Entrepreneurship \& Regional Development, 5(3), 315-330.

Krueger Jr, N. F., Reilly, M. D., \& Carsrud, A. L. (2000). Competing models of entrepreneurial intentions. Journal of business venturing, 15(5-6), 411-432.

Liñán, F., \& Chen, Y. W. (2009). Development and cross-cultural application of a specific instrument to measure entrepreneurial intentions. Entrepreneurship theory and practice, 33(3), 593-617.

Low, M. B., \& MacMillan, I. C. (1988). Entrepreneurship: Past research and future challenges. Journal of management, 14(2), 139-161.

Lu, G., Song, Y., \& Pan, B. (2021). How university entrepreneurship support affects college students' entrepreneurial intentions: An empirical analysis from China. Sustainability, 13(6), 3224.

Luszczynska, A., Scholz, U., \& Schwarzer, R. (2005). The general self-efficacy scale: multicultural validation studies. The Journal of psychology, 139(5), 439-457. 
Mahfud, T., Triyono, M. B., Sudira, P., \& Mulyani, Y. (2020). The influence of social capital and entrepreneurial attitude orientation on entrepreneurial intentions: the mediating role of psychological capital. European Research on Management and Business Economics, 26(1), 33-39.

Meoli, A., Fini, R., Sobrero, M., \& Wiklund, J. (2020). How entrepreneurial intentions influence entrepreneurial career choices: The moderating influence of social context. Journal of Business Venturing, 35(3), 105982.

Messeghem, K. (2003). Strategic entrepreneurship and managerial activities in SMEs. International Small Business Journal, 21(2), 197-212.

Morales, C. E., \& Holtschlag, C. (2013). Post materialist values and entrepreneurship: a multilevel approach. International Journal of Entrepreneurial Behavior \& Research.

Noorderhaven, N. G., Wennekers, A. R. M., Thurik, A. R., \& van Stel, A. (2004). Selfemployment across 15 European countries: the role of dissatisfaction. Entrepreneurship: Theory and Practice, 29(1), 447-466.

Newbery, R., Lean, J., Moizer, J., \& Haddoud, M. (2018). Entrepreneurial identity formation during the initial entrepreneurial experience: The influence of simulation feedback and existing identity. Journal of Business Research, 85, 51-59.

Parboteeah, K. P., Hoegl, M., \& Cullen, J. B. (2008). Ethics and religion: An empirical test of a multidimensional model. Journal of business ethics, 80(2), 387-398.

Perez-Quintana, A., Hormiga, E., Martori, J. C., \& Madariaga, R. (2017). The influence of sex and gender-role orientation in the decision to become an entrepreneur. International Journal of Gender and Entrepreneurship.

Pyszczynski, T., Greenberg, J., Solomon, S., Arndt, J., \& Schimel, J. (2004). Why do people need self-esteem? A theoretical and empirical review. Psychological Bulletin, 130, 435468

Reynolds, P. D. (1992). Sociology and entrepreneurship: Concepts and contributions. Entrepreneurship theory and practice, 16(2), 47-70.

Rosenberg, M. (1965), Society and the Adolescent Self-image, Princeton, NJ: Princeton University Press.

Rusu, V. D., \& Dornean, A. (2019). The quality of entrepreneurial activity and economic competitiveness in European Union countries: a panel data approach. Administrative sciences, $9(2), 35$.

Schein, V. E., Mueller, R., Lituchy, T., \& Liu, J. (1996). Think manager-think male: A global phenomenon? Journal of organizational behavior, 17(1), 33-41.

Schlaegel, C., \& Koenig, M. (2014). Determinants of entrepreneurial intent: A meta-analytic test and integration of competing models. Entrepreneurship Theory and Practice, 38(2), 291-332. 
Shinnar, R. S., Hsu, D. K., \& Powell, B. C. (2014). Self-efficacy, entrepreneurial intentions, and gender: Assessing the impact of entrepreneurship education longitudinally. The International Journal of Management Education, 12(3), 561-570.

Stephan, U., \& Uhlaner, L. M. (2010). Performance-based vs socially supportive culture: A cross-national study of descriptive norms and entrepreneurship. Journal of International Business Studies, 41(8), 1347-1364.

Thurik, R., \& Dejardin, M. A. F. G. (2011). The impact of culture on entrepreneurship. The European Business Review, 1(2), 57-59. 